\title{
goranska kajkavština
}

Izvorni znanstveni rad

UDK 811.163.42'282 : Fužine (091)(497.5)

Primljeno 2018-04-05

Prihvaćeno za tisak 2018-08-29

\section{PRILOZI ZA ISTRAŽIVANJE OSNOVNOG KAJKAVSKOG GOVORA U FUŽINAMA U GORSKOM KOTARU}

(Istraživački rad o podlozi govora župe Fužine, s osvrtom na formiranje i transformacije starosjedilačkih obitelji tijekom 18. i 19. stoljeća)

Zlata Bujan-Kovačević, Zagreb /Samobor

\section{Sažetak}

Na temelju antroponimijske literature, matičnih knjiga i dokumenata župe Fužine autorica svojim istraživanjem o ženidbama kajkavaca s čakavcima $i$ štokavcima dokazuje da je stara osnova, tj. supstrat govora u najzapadnija tri hrvatska kajkavska mjesta (Fužine, Vrata, Belo Selo) kajkavština pokupske provenijencije, koja se tijekom vremena u 18. i 19. st. mijenja pod priljevom čakavaca, dok štokavski govor susjednog Liča nema nikakva utjecaja.

Od prvoga popisa stanovništva sredinom 18. st. do početka 20., u kojem je značajan skoro potpuni gubitak domaćega govora, ovaj je idiom, ako se jednakopravno istražuje u kajkavskim kućama i kućama s miješanim brakovima, doista kajkavski, a ne čakavskokajkavski kako ga pogrešno i pred stotinu godina i danas običavaju prikazati.

Ključne riječi: kajkavski supstrat fužinarskog govora; ženidbe s čakavcima; pouzdaniji informatori; originalna prozodija; Rački i Strohal kao krivi uzori

Premda prava Zagrepčanka, odrađujući dug govoru svoje majke iz mjesta Vrata, u kojem sam se slučajem i ja rodila, u više navrata bavila sam se skupljanjem njegovih razlikovnih karakteristika prema standardu. Ne samo da sam u nekoliko zbirki uvrstila oko stotinu pedeset pjesama na tom idiomu (a ostavila sam i njihov tonski zapis) već sam pripremila i mali rječnik tog izričaja, a potom sa Silvijom Polak i malu knjižicu najpoznatijih izreka. 
Osnovni kajkavski govor općine Fužine, kako svjedoče matične knjige u župi, došao je s prvim govornicima iz pokupskog kraja u prva tri naselja kao najzapadniji odvjetak kajkavaca koji graniči s primorskim čakavskim govorom u zaselku Benkovac. Tu je točka susreta dvaju dijalekata koja počinje danas primorskim, nekad goranskim mjestom Zlobin na cesti prema Bakru i Rijeci. Fužina (u jednini, najraniji zapis i domaći govor to potvrđuju) jest goransko kajkavsko naselje - zaključiti je najprije po tome što se i dandanas, kad više i nema domaćega govora, osim u tragovima, nazivaju kajkavcima. Zaključiti je, zatim, po tome što su prve kuće, prvi stanovnici od početka 18. stoljeća odreda bili kajkavci. Sva se prva kajkavska prezimena u župnim knjigama od 1725. i u popisu iz 1751. ubiciraju ranije u sjeveroistočnijim krajevima Gorskog kotara, dakle prema Kupskoj dolini, što je vidljivo iz istraživanja A. Burića, a osobito u starijim potvrdama R. Lopašića. Dakle, kajkavski su govornici. Sve do danas u vrlo visokom se postotku točno znade podrijetlo uobičajenih pojedinih prezimena, samo što se govor tijekom vremena u nekima od ovdašnjih kajkavskih kuća više ili manje približavao čakavskom, čemu su razlog ženidbe i udaje. S promijenjenim imenom, mjesto Fužine (sada u množini) postaju veće naselje tek od kraja 17. stoljeća, a osobito se razvijaju nakon završetka gradnje ceste Karoline od Karlovca do Bakra, Sušaka i Rijeke g. 1726.

Kao putna postaja Fužina je prvi put zabilježena u jednom frankopanskom pismu g. 1647. a župa i njeni dokumenti datiraju od 1725. Na istoj cesti udaljena samo par kilometara sjeveroistočno u istoj općini kajkavska su Vrata i Belo Selo, naselja formirana krajem 18. st. na koja se naslanja čakavska Slavica iz istog vremena. Utjecaj štokavštine bliskog, južno smještenog mjesta Lič, koje danas spada u općinu Fužine, nije nikada bio značajniji za ovaj govor. Zbog preokrenutih suvremenih percepcija i ponekad netočno prenijetih osobina, pa čak i tvrdnji da je fužinarski govor goranski čakavski, bila sam ponukana prihvatiti se ovog istraživanja. Sve do danas, makar je gubitak domaćega govora zamalo dovršen, dobro se znade koje su kuće kajkavske, koje čakavske u svim mjestima te općine. Istina je, ponavljam, da se ovaj govor mijenjao tijekom vremena, poprimajući sve više čakavskih osobina. Zaista postoje jaki utjecaji čakavskog i na Belom Selu, u Vratima i Fužini, ali on je izrazitiji u onim kućama u koje su se ženili ili udavali čakavci pa takve miješane obitelji nikako nisu mjerilo $z \boldsymbol{a}$ cjelinu kajkavštine i njenu stvarnu sliku, premda su me suvremeni istra- 
živači goranskih govora upozorili: “... čini se, prema podacima koje ste naveli, da taj govor uistinu ima kajkavsku podlogu, no ne smije se zanemariti i ignorirati noviji čakavski (i štokavski) upliv zbog kojeg je govor danas takav kakav jest $i$ to je činjenica koja je dijalektolozima najvažnija - vjerno stanje na terenu u trenutku istraživanja."

Moje je mišljenje da bi u fužinarskom slučaju svaki istraživač domaćega kajkavskog govora morao imati više discipline u traženju istinske kajkavske jezgre, jer u kajkavskim kućama ona se neizmijenjeno objelodanjuje i diferencira danas kao i prije. I u oblicima, i u naglascima, uvijek drugačijim nego u čakavskom, pa čak ako je u leksiku prihvaćena istoznačnica, ona ima drugačiji akcent. Ne mislim da dosadašnji istraživači nisu učinili mnogo da se opiše naš govor, ali su zanemarili izvornost onog govora o kome je ovdje, čak i u sadašnjem trenutku, riječ. U današnjem stanju kajkavštine na Fužini jedna kuća s čakavskim pređima ne može biti slika ovoga govora. Primjerice: uzima se kao važna karakteristika oblik ZÀMEN, ZÀMI od glagola ZÊT, koji nije istinsko mjerilo za fužinarski govor, jer se još uvijek u kajkavskoj kući kaže: ZÊMEN, ZÊMI. A tako je i u nekim drugim važnim slučajevima.

Prihvativši kao gotovost pohvalu dr. Andrije Račkog (Iz prošlih dana općine Liča i Fužine, Sušak, 1948.) koji se u ime "milozvučne čakavštine"(njegov navod!) odrekao istine da su Fužine kajkavski kraj, griješe i dalje oni koji se usude ovoj kajkavštini, iako u njoj ima čakavskih osobina više nego u ikojem drugom govoru, pridijevati ime "čakavskokajkavski govor". Rački piše, a to vrijedi za njegovo vrijeme, kako fužinsko žiteljstvo predstavlja heterogenu masu, jer se doselilo iz raznih krajeva "pa se u Fužini čuje uz blagoglasnu čakavštinu i kajkavski dijalekt”. Posvema je zaboravio, ili zanemario, ili nije ni bio svjestan da su čakavci mahom pridošlice, superstrat, a ne supstrat. Taj teolog, koji je živio i radio na Trsatu, gdje se srodio s čistom čakavštinom, sam izjavljuje: "U Fužini bolje obitelji, ili one koje bi rad da ih se smatra boljima i naprednijima, zaziru od kajkavštine te vole govoriti čakavskim narječjem. Kajkavsko je po njihovom sudu nepodesno za čovjeka boljeg odgoja i šire vaspitanosti”. Istina je što kaže, ali viđenije obitelji i njihova malobrojnost nisu ni u njegovo doba, početkom 20. st., bili mjerilo mjesnog - prema glavnim osobinama kajkavskoga - govora.

Kako još pojasniti mišljenje ovog Fužinarca čije je prezime goransko 
kajkavsko iz predjela oko Kupe i Dobre? Njegov predak Anton Rački, rođen 1708. pojavljuje se među prvim fužinarskim naseljenicima koji svi odreda govore kajkavski, što potvrđuje prvi popis stanovništva i čemu svjedoče matične knjige. U prve dvije generacije njegovi se kajkavci žene kajkavkama (Švob i Blažević), ali u trećoj i četvrtoj čakavkama iz Primorja (Stupar i Miloš). Andrijin otac i djed bili su dakle pod utjecajem čakavskih majki, a obitelji boljeg stanja, trgovci i posjednici kakva je bila upravo ta obitelj i nadalje se priklanjaju čakavštini. Dakle, iako mu je majka kajkavka (Štanfel), Andrija će i kućnim jezikom (budući da muški članovi gotovo uvijek slijede govor oca, a ne majke, dok djevojke obično govore oba govora u miješanim obiteljima) i školom i poslom prigrliti čakavski i dati mu prvenstvo.

Kako se priljev pretežno očeva čakavaca odrazio na mijene u govoru trebali bi izvidjeti novi istraživači, ali svakako uspoređujući pravi kajkavski govor s onim povećanih čakavskih alijeteta. Ove prve ne bi trebale biti iz obitelji koje su miješane, već iz onih koje se prepoznaju kao kajkavske (dok ih uopće još mogu naći, jer govor se gasi). Kako je već rečeno, kajkavski se govorilo ponajveć u seoskom življu, što potvrđuje Andrija Rački. Stoga njegov kućni govor, da ga je igdje zapisao, ne bi mogao biti primjeren fužinarski govor.

I genealoški slijed Andrije Franje Račkog iz iste obitelji, povjesničara i tajnika Jugoslavenske akademije, koji je prigrlio standard (čak i za svoje pjesme), pokazuje kako su se odvijali utjecaji u miješanim obiteljima: Franjo Rački, povjesničar, r. 25.11.1828. od oca Grge, r. 1798. i majke Margarete Padavić, djeda Blaža, r. 1739. suca, i Antonije, udovice iz Bakra (nepoznato prezime) i pradjeda Antona, r. 1708. iz Kostela i Fužinarke, kajkavke, Barbare Švob. Viđenija obitelj, uglavnom obrtnička, muškim podrijetlom iz kajkavskog kraja, kako se ovdje vidi, imala je ženidbene veze s čakavskim govornicama, samo mu je prabaka kajkavka. Kako ovaj fužinarski velikan nije pridavao važnost domaćem govoru, na njemu nije ništa ni pribilježio.

Ovi primjeri trebali bi poslužiti onima koji će se baviti utvrđivanjem kajkavskih temelja što su preživjeli kao kajkavske osobine na ovoj posebnoj najzapadnijoj kajkavskoj liniji. Prema mome mišljenju, preokrenuta percepcija podrijetla, provlačenje mišljenja o istovrijednosti i jednakoj zastupljenosti kajkavskog i čakavskog dovelo je do toga da se danas mnogi 
kolebaju fužinskom govoru priznati kajkavštinu, a u njoj ima gotovo isti broj osobina sličnih slovenskom govoru, pa nitko ne sumnja da je ovaj pokupski govor ikada bio dio slovenštine. Današnji žurnalistički nastrojeni i sasvim neinformirani književni kritičari olako će jezgru goranskih pjesnika koji stvaraju na svojim zavičajnim idiomima (npr., A. Žagar iz Zamosta, Z. Pochobradsky iz Čabra, J. Z.Čadež iz Ravne Gore, F. Švob iz Fužina) bez okolišanja proglasiti govornicima goranskog čakavskog. Čak se i na učilištu u Rijeci izvodi kako je čakavski prvotni fužinarski goranski govor.

I još nešto, nije potpuno istinita ni tvrdnja da je lokvarsko-fužinarski jedan govor, kako je tvrdio R. Strohal pred više od stotinu godina, a mnogi prihvatili. Ima tu znatnih razlika, koje i kolike - nekom istraživaču predstoji da nam to predoči. Tamo su se naselile druge, doduše isto tako kajkavske porodice, ali tamo su donijete i razvile su se drugačije osobine u glasovima i oblicima i nije vjerojatno da se preko jednog brdašca navodni zajednički govor u svome rastu tako lako iz osnova promijenio, pa se razlikuje i danas. Prema župnim maticama u tom sjevernijem mjestu također prevladavaju prezimena pristigla iz sjeveroistočnijih kajkavskih krajeva, dok se čakavci i tu javljaju sporadično. Zanimljiva je činjenica da je jezgra prvotnih, pa i današnjih lokvarskih prezimena potpuno drugačija od fužinarske, da je vrlo malo istih prezimena u Fužinama i Lokvama (čak i nakon 200-tinjak godina bliskog susjedstva i ženidbi niti 20 posto).

Koju sam metodu upotrijebila, da bih pokazala kako se radi uistinu o osnovnom kajkavskom govoru? Prvo, sama sam istraživala razlike govora u kajkavskim i čakavskim kućama. I kad sam pisala poeziju ili prozu, posizala sam za dubljim tragom izvorna govora, imajući pri tom savršenu informatoricu, svoju sjajnu, bistru tetu Ljubicu Bujan udatu Petrović, dakako i još nekih šest-sedam drugih, koja je u svojoj kući imala dva govora, očev čakavski, majčin kajkavski. Ona je dobro razlikovala oba govora, nikad nije imala nikakve sumnje kako se što kaže na jednom i drugom. Pa i kad su oblici bili isti, naglasci su se razlikovali i nisu se mijenjali. Ničeg novog, promjenjivog, već ustaljeno kajkavskog i čakavskog bilo je u njenim iskazima, i to bez ikakvih kolebanja. A kako se prozodija dobro sačuvala, još se čuva i ne mijenja se kroz sve vrijeme postanka ovih naselja, po njoj bi istraživač trebao zaključiti pravo podrijetlo kućnog izričaja, jer isti 
oblici u dva se govora, kajkavskom i čakavskom, različito akcentuiraju.

Dakako da se slika današnjeg stanja promijenila, ionako se više ne može naći dijete koje bi na Lidranu interpretiralo pravi domaći govor, ili se pojavi tek koji izuzetak. Razlog je tomu da on danas živi još u vrlo malom broju kuća. Najveća prijetnja mu je izjednačavanje prema standardu i manje prema čakavskom. Najdrastičniji je u tomu današnji oblik 3. lica futura glagola biti - budu, umjesto bôjo/bôdo (pretpostaviti je porijeklo iz kajkavskih/i slovenskih krajeva). Ovog posljednjeg jedva da se sjeća itko, osim potvrde koju sam dobila sedamdesetih godina prošlog stoljeća od pokojne Jušte Mihaljević, udate Maksan, rođene 1892.g. Indikativno je da u ostalim licima svi sasvim besprijekorno govore starim oblikom: bôn, bôš, bô, bômo, bôšte, ali neizostavno kažu: BUDU!!!

Drugo, primila sam se ovog posebnog istraživanja tako da sam obradila ženidbe koje pokazuju kako se govorilo od prvih naseljenih obitelji koje su nedvojbeno kajkavske provenijencije, i zatim se pomalo povećavao priljev čakavskih i štokavskih govornika do početka 20. stoljeća. Razdoblje 20. stoljeća ne može biti presudno za mijenjanje kajkavskih/čakavskih osobina. Tada naime, u prvoj polovici stoljeća, domaći govor ubrzo nestaje novim pritjecajem stanovništva, a u drugoj se polovici gasi u međusobnom razgovoru. Zaključiti je da se govorilo prvotno donesenim kajkavskim, onim koji se nije drastično, već samo djelomice, promijenio u tri stotine godina boravka u Fužini u onim kućama u kojima nije bilo značajnijih priljeva čakavskih mladoženja i nevjesti. Na to su trebali raniji istraživači biti upozoreni, razlike su vidljive, a to mi je bila namjera. Na nekim budućim istraživačima leži teret da se razluči kajkavski od čakavskoga u tom kajkavskom fužinarsko-vratarsko-beloselskom idiomu.

Predmet su ovog istraživanja ženidbene veze koje indiciraju kako se u kojoj obitelji govorilo. Matice rođenih i ženjenih i stališi duša župe u tome su mi poslužili, jer iz njih se iščitava porijeklo pojedinih porodica kao i svaki novi čakavski dolazak u fužinarski kraj među kajkavske obitelji. Posebno sam obratila pažnju da li je bilo i koliko čakavskih ili štokavskih dolazaka u kajkavsku kuću bilo s ženikove, bilo s nevjestine strane.

Morala sam eliminirati strance, bar one koji nisu uopće ostavljali potomaka u župi, a ponavljam, nisam analizirala 20. stoljeće, jer je to doba gašenja upotrebe domaćeg govora. Uzrok je tome svakako i školovanje u fužinskoj školi osnovanoj 1785. g., a time i nastojanje da se ne govori 
"prostim seoskim govorom". Pismenost ranog doba nije ostavila tragova, a ionako je pripadala samo odabranima, a ti su dolazili s primorske strane: službenici, svećenici, obrtnici koji su si čak uzimali toliko slobode (župnik, na primjer) da neka prezimena izmijene prema njima poznatijim, primorskima. Morala sam zanemariti i stanovit broj obitelji u kojima zbog župnikove nemarnosti nisu zabilježena prezimena nevjesti, pa se prema tome ne može razaznati odakle su, ali toga nije moglo biti više od 2-3 posto, što ne mijenja osnovnu sliku. U konačnici, pri pregledu postotaka obitelji čistih kajkavaca, čakavaca i štokavaca, a osobito pri analizi miješanih brakova, vidljivo je koji je osnovni govor prvih stanovnika, a to je svakako onaj kajkavaca iz pokupskih krajeva, a tek zatim dolaze čakavski utjecaji, i to ne prije kraja 18. stoljeća.

\section{Popis literature:}

BARAC-GRUM, Vida - FINKA, Božidar: Govori i nazivlje (Gorski kotar, monografija, Delnice, 1981.)

BUJAN-KOVAČEVIĆ, Zlata: Fužinarski kaj, prilog rječniku goranskih govora (Delnice, 1999.) BUJAN-KOVAČEVIĆ, Z. - POLAK S.: Ni ke kaj kan klast, fužinarske izreke (Fužine, 2004.)

BURI, Antun: Povijesna antroponimija Gorskog kotara u Hrvatskoj, goranska prezimena kroz povijest (Rijeka, 1983.)

LISAC, Josip: Susret čakavskog, štokavskog i kajkavskog narječja (Fužine, monografija, 1985.)

POLAK, Silvija: Govor Fužina u dijalekatskoj klasifikaciji (Diplomski rad, 2002.)

RAČKI, Andrija: Iz prošlih dana općine Liča i Fužine (Sušak, 1948.)

\section{Izvori:}

1/ Matice rođenih župe Fužine (1725-1778, 1778-1857, 1858-1889)

2/ Matice ženjenih župe Fužine (1728-1804, 1815-1858, 1858-1943)

3/ Matice umrlih župe Fužine (1726-1815, 1815-1857, 1858-1888, 1888-1916)

4/ Popis krizmanih župe Fužine (1726-1818)

5/ Matice susjednih župa (Lokve, Bakar, Novi Vinodolski, Hreljin i sl.)

6/ Stališi duša župe Fužine:

I (1768)

II (1788 - nestao pred 10 godina, djelomice obradila ranije),

III (1795)

IV (1761-1850)

V (1815-1 862)

VI (1870 cca - $1910 \mathrm{cca})$

7/ Popis gospodara (kuća) u Fužinama iz god. 1751.

\section{Prilozi:}

Obiteljski govori u postocima: A/Prvi naseljenici (prema popisu 1751.); B/Starosjedioci kroz 18. st.; C/Pridošlice krajem 18. st.; D/Stanovništvo u 19. st.; F/Detaljna analiza svih obitelji sobzirom na govor u razdoblju 18. i 19. st. 


\section{OBITELJSKI GOVORI U POSTOTCIMA sveukupno obrađeno 1205 obitelji}

LEGENDA: K/K (oba roditelja kajkavci), Č/Č (oba čakavci) Č/K (čakavac i kajkavka), ک̌/Č (štokavac i čakavka), Kč/K (muž po ocu kajkavac, po majci čakavac; Č/Čk (žena po ocu čakavka, po majci kajkavka) i tsl.

\begin{tabular}{|c|c|c|}
\hline \multicolumn{3}{|c|}{ A/ PRVI NASELJENICI, 42 obitelji } \\
\hline $\begin{array}{l}\text { Glavari kuće } \\
\text { posjednici }\end{array}$ & ženjen brat, sin/ neženjen brat, sin/ & GOVOR \\
\hline KAUZLARIĆ Marko & 1 & K \\
\hline ŠVOB Andre & 1 & $\mathrm{~K}$ \\
\hline ŠVOB Miha & & $\mathrm{K}$ \\
\hline ABRAMOVIĆ Dora udova & 1 & $\mathrm{~K}$ \\
\hline LISAC Petar & 1 & $\mathrm{~K}$ \\
\hline ČEBUHAR Jakob & 1 & $\mathrm{~K}$ \\
\hline KAUZLARIĆ Miha & 1 & $\mathrm{~K}$ \\
\hline KLOBUČAR Anton & 2 & $\mathrm{~K}$ \\
\hline BLAŽEVIĆ Blaž & & $\mathrm{K}$ \\
\hline KOZELIČKI Andre & & K \\
\hline FIŠTER Mate & 1 & $\mathrm{~K}$ \\
\hline TOMAC Luka & 1 & $\mathrm{~K}$ \\
\hline RAČKI Anton & & $\mathrm{K}$ \\
\hline KAUZLARIĆ Anton & & $\mathrm{K}$ \\
\hline KAUZLARIĆ udova Jureta & 1 & $\mathrm{~K}$ \\
\hline BLAŽEVIĆ Matija & 1 & $\mathrm{~K}$ \\
\hline PAVLIĆ Matija & 1 & $\check{S} / \check{C} ?$ \\
\hline OŽURA Anton & & $\mathrm{K}$ \\
\hline MIHALJEVIĆ Jure & 1 & $\mathrm{~K}$ \\
\hline KAUZLARIĆ Jure & 1 & $\mathrm{~K}$ \\
\hline BLAŽEVIĆ udova Jureta & & $\mathrm{K}$ \\
\hline KOVAČIĆ Bartol iz Bakra & & $\check{C}$ \\
\hline KLOBUČAR Grga & 1 & $\mathrm{~K}$ \\
\hline ŠTIMAC Jure & 1 & $\mathrm{~K}$ \\
\hline PROŠEN udova Petra & 1 & $\mathrm{~K}$ \\
\hline BLAŽEVIĆ Ivan & & $\mathrm{K}$ \\
\hline GOLAC Grga & & $\check{S}$ \\
\hline GOLIK Grga & & $\mathrm{K}$ \\
\hline LUKINI Josip iz Bakra & & $\check{C}$ \\
\hline ŠVOB Jure & & $\mathrm{K}$ \\
\hline
\end{tabular}

Od 30 kuća: kajkavskih 26, čakavskih 2, štokavskih 2

Ravno 30 posjednika (i još 9 njihovih oženjenih neidentificiranih parova), tome treba dodati i obitelji koje su već u to doba naseljene i ostavile potomke, a ne nalaze se na ovom popisu (bilježim prema Matici umrlih od 1726. do 1735.):

BUDISELIĆ 


$\begin{array}{lc}\text { FICLIN } & \mathrm{K} \\ \text { FORENBACHER } & \check{C} \\ \text { GAŠPARAC } & \mathrm{K} \\ \text { GOLIĆ } & \check{C} \\ \text { GRENKO } & \mathrm{K} \\ \text { KARLOVIĆ } & \check{C} \\ \text { KVATERNIK } & \mathrm{K} \\ \text { MANCE } & \mathrm{K} \\ \text { MAUROVIĆ } & \mathrm{K} \\ \text { ŠTANFEL } & \mathrm{K}\end{array}$

Od 12 obitelji kajkavaca 8 , čak. 3, štok. 1

Zbir i postotak prvih 42 obitelji:

$\begin{array}{ll}\text { kajkavaca 34, } & \text { ili } 81 \% \\ \text { čakavaca 5, } & \text { ili } 12 \% \\ \text { štokavaca 3, } & \text { ili } 7 \%\end{array}$

\section{B/ STAROSJEDIOCI kroz 18. st. 899 obitelji}

Kako su se obitelji umnažale, jer je promet na Karolini cvao, postotak kajkavskih se uvećao u odnosu na prve popise. Gotovo do kraja 18. stoljeća govorilo se kajkavski ovako:

$\begin{array}{lcc}\text { Kajkavski s očeve strane } & 854 \text { obitelji } & 94,4 \% \\ \begin{array}{l}\text { Kajkavski s majčine strane } \\ \text { Od toga: }\end{array} & 606 \text { obitelji } & 67,4 \% \\ \begin{array}{l}\text { Očevi i majke kajkavci } \\ \text { Očevi kajkavci s čak. natruhama, } \\ \text { majke kajkavke }\end{array} & 561 & 46,5 \% \\ \begin{array}{l}\text { Očevi kajkavci, majke čakavke } \\ \text { Očevi kajkavci, majke štokavke }\end{array} & 11 & 0,9 \% \\ \begin{array}{l}\text { Očevi čakavci, majke kajkavke } \\ \text { Očevi i majke čakavci }\end{array} & 52 & 19 \% \\ & 27 & 4,3 \% \\ \text { Očevi štokavci, majke kajkavke } & 9 & 2,2 \% \\ \text { Očevi štokavci, majke čakavke } & 7 & 0,7 \% \\ & 5 & 0,6 \% \\ & & 0,4 \%\end{array}$

\section{C/ PRIDOŠLICE krajem 18.st. - 122 nove obitelji}

Dodamo li pridošlice krajem 18. st. pristiglih uglavnom zbog radova na pruzi, slika se mijenja zbog priljeva čakavaca: Porast kajkavskog u očevini je tek za 21 obitelj, u majčinskom za 77, jer su se priženili mnogi od čakavaca, pa je broj obitelji s čakavcem ocem i kajkavskom majkom povećan. I broj izvornih čakavskih govornika s očeve i majčine strane sa 36 naglo je porastao na 100 obitelji.

Vidi se pad postotka kajkavskoga govora: Očevina, dakle, na kraju 18. st. govori kajkavski u 875 obitelji, dakle sada $80 \%$, a u materinjem kajkavski u 683 obitelji, dakle $62,5 \%$. Vidljiv je i pad prema ranijem govoru u pojedinim obiteljima.

Od toga su:

Očevi i majke kajkavci

Očevi kajk./čak. natruhe, majke kajk.

Očevi kajkavci, majke čakavke

$\begin{array}{ll}18 & 1,5 \% \\ 3 & 0,2 \% \\ 10 & 0,8 \%\end{array}$




$\begin{array}{lcc}\text { Očevi i majke čakavci } & 21 & 1,7 \% \\ \text { Očevi čakavci, majke kajkavke } & 40 & 3,3 \% \\ \text { Očevi čakavci, majke štokavke } & 3 & 0,2 \% \\ & & \\ \text { Očevi štokavci, majke kajkavke } & 16 & 1,3 \% \\ \text { Očevi štokavci, majke čakavke } & 8 & 0,7 \%\end{array}$

\section{D/ STANOVNIŠTVO u 19. st. - 193 pridošle nove obitelji}

Nove, sasvim kajkavske obitelji u ovom razdoblju manje su porasle nego čakavske, omjer 25:35, očevi kajkavci manje nego čakavci, omjer 11 : 86, dok je majki kajkavki razmjerno više nego čakavki, omjer 111:46.

Od toga:

Očevi i majke kajkavci

Očevi kajkavci, majke čakavke

Očevi i majke čakavci

Očevi čakavci, majke kajkavke

Očevi štokavci, majke kajkavke

$\begin{array}{ll}25 & 2 \% \\ 11 & 1 \% \\ 35 & 3 \% \\ 86 & 7 \% \\ 11 & 0,9 \%\end{array}$

F/ Slijedi detaljna analiza obiteljskoga govora u svakoj osnovanoj obitelji (njih 1205) u 18. i 19. stoljeću. Ovdje prilažem pogled samo na granu najbrojnije obitelji, prema nadimcima njihove kuće:

ABRAMOVIĆI

KAUZLARIĆ Andre, 16 nov 1735 /11 feb 1771/ŠVOB Antonija

$\mathrm{K} / \mathrm{K}$

KAUZLARIĆ Andre, 16 nov 1811/1841>/STIPANOVIĆ Antonija

KAUZLARIĆ Anton 22 feb 1861/21 jun 1885/KRAJAČIĆ Josipa K/K

KAUZLARIĆ Anton, 5 oct $1771 /<1808>/$ KOVAČIĆ Katarina

KAUZLARIĆ Anton, 8 jul 1730/<1748>/ČEBUHAR Marija

KAUZLARIĆ Anton, 8 jul 1780//PAVLIĆ Polona

KAUZLARIĆ Bartol, 8 jun 1718// PAVLIĆ Margareta

KAUZLARIĆ Blaž, 4 feb 1818/23 nov 1837/ ČEBUHAR Antonija

KAUZLARIĆ Dragutin, 31 oct34 / 4 nov55/ BLAŽEVIĆ Franka

KAUZLARIĆ Filip, 30 apr 1861/12 jul 1888/ STARČEVIĆ Jelena

KAUZLARIĆ Franjo, 23 sep 1844 /26 feb 1865/ ŠVOB Vicenca

KAUZLARIĆ Ivan, 1 jul 1843/<1881>/ ŠVAST Julijana

KAUZLARIĆ Ivan, 9 jan 1772/20 nov 1793/LISAC Marija

KAUZLARIĆ Izidor, 5 apr 1866/6 jul 1890/BUBANJ Ursula

KAUZLARIĆ Josip, 1775/13 nov 1799/ABRAMOVIĆ Polona

KAUZLARIĆ Josip, 1819/18 sep 1854/BUTKOVIĆ Jela

KAUZLARIĆ Juraj, 27 mar 1853/25 aug 1879/ OŽURA Antonija

KAUZLARIĆ Jure, 19 dec1749/15 feb 1773/ KLOBUČAR Marija Micka

KAUZLARIĆ Jure, 19 dec 1749 //KAPLAN Ana

KAUZLARIĆ Lovro, 5 aug 1787/<1810>/ ŠIKIĆ Marija

KAUZLARIĆ Martin 22 oct 1811// KAUZLARIĆ Matejka

KAUZLARIĆ Matija, 19 feb 1765/26 nov 1789 /ABRAM. Marija

KAUZLARIĆ Matija 19 feb 1785 <1805>/ MIHALJEVIĆ Marija
$\mathrm{K} / \check{C}$
$\mathrm{K} / \check{C}$
$\mathrm{K} / \mathrm{K}$
$\mathrm{K} / \check{S}$
$\mathrm{K} / \mathrm{S}$
$\mathrm{K} / \mathrm{K}$
$\mathrm{K} / \mathrm{K}$
$\mathrm{K} / \check{S}$
$\mathrm{K} / \mathrm{K}$
$\mathrm{K} / \mathrm{K}$
$\mathrm{K} / \mathrm{K}$
$\mathrm{K} / \check{C}$
$\mathrm{K} / \mathrm{K}$
$\mathrm{K} / \check{C}$
$\mathrm{K} / \mathrm{K}$
$\mathrm{K} / \mathrm{K}$
K/Č
$\mathrm{K} / \mathrm{K}$
$\mathrm{K} / \mathrm{K}$
$\mathrm{K} / \mathrm{K}$
$\mathrm{K} / \mathrm{K}$ 
KAUZLARIĆ Matija, 20 feb 1819/<1845>/ BELJAN Elizabeta KAUZLARIĆ Matija, 26 feb 1865/11 aug 1892/RANDELJ Antonija KAUZLARIĆ Miha, 9 aug 1777/<1810>/ ABRAMOVIĆ Ana KAUZLARIĆ Miha,28 sep 1834/29 apr 1861/ŠVOB Margareta KAUZLARIĆ Miho, 20 sep 1857 /30 jun 1881/ BUBANJ Dorka KAUZLARIĆ Nikola, 8 oct 1804 //KOVAČIĆ Marija KAUZLARIĆ Pavle, 10 jan 1842/2 may 1869/KAUZLARIĆ Marija KAUZLARIĆ Stjepan 28 jul 1806 /18 nov 1833/KAUZLARIĆ Jela KAUZLARIĆ Toma, 12 dec 1835/2 jun 1867/ ŠVAST Antonija BALVANI/BERKINI

KAUZLARIĆ Andre, 25 nov 1812/ 26 sep 1838 VANČINA Marija KAUZLARIĆ Anton $<1820>/ 2$ feb 1846/ ŽUPANČIĆ Franka KAUZLARIĆ Bartol,BERKE 8 jun 1718//PAVLIĆ Margareta KAUZLARIĆ Blaž, 11 feb 1751/<1805>/ GRENKO Katarina KAUZLARIĆ Grga, 27 feb 1747/4 feb 1771/MIHALJ. Magdalena KAUZLARIĆ Grga, 5 mar 1756 /2 feb 1777/ KAUZL.LUK. Jela KAUZLARIĆ Ivan, 22 dec 1808/17 feb 1833/ RAČKI Marija KAUZLARIĆ Ivan, 7 mar 1847/14 may 1871/ POŽARIĆ Ivana KAUZLARIĆ Josip, 11 mar 1810//PAVLETIĆ Matejka KAUZLARIĆ Jure Babin, 11 apr 1765/1 nov 1786/ABRAMOVIĆ Jela KAUZLARIĆ Jure, 11 apr 1786/<1813>/RANDELJ Katarina KAUZLARIĆ Jure, 20 apr 1720 // GRENKO Ana KAUZLARIĆ Martin, 22 jul 1730/17 feb 1754/KLOBUČAR Jela KAUZLARIĆ Mate, 9 feb 1816/11 feb 1846/KAUZLARIĆ Franka KAUZLARIĆ Matija <1755>/31 jan 1779/ ABRAMOVIĆ Margareta KAUZLAR Miha Balvan, 11 sep 1782/28 jan 01/DOMČIĆ Ana KAUZLARIĆ Miha Balvan, 11 sep 1782 //ŠTANFEL Jela KAUZLARIĆ Stjepan, 1762 /27 feb 1786/KAUZLARIĆ Lucija CICMANI

KAUZLARIĆ Anton, 25 may 1834/21 sep 62/ KLOBUČ. Marija KAUZLARIĆ Anton, 6 jan 1777/14 jun 1818/ KRŠEVAN Ursula KAUZLARIĆ Blaž CICMAN, 2 feb 1724/<1750>/ČOP Katarina KAUZLARIĆ Gašpar, 5 jan 1830/1 jul 55 /PIVAC Kata

KAUZLARIĆ Gašpar, 5 jan 1830//POLIĆ Kata

KAUZLARIĆ Gašpar, 5 jan 1830//KARLIĆ Marija

KAUZLARIĆ Ivan Anton, 20 may 1843/ 27 jun 65/BLAŽ. Marija KAUZLARIĆ Ivan Anton, 20 may 1843//CRNKOVIĆ Marija KAUZLARIĆ Ivan, 14 jul 1814/22 nov 1838/GOLIK Jela KAUZLARIĆ Ivan, 2 mar 1841 / 10 jul 1867/ MIHALJEVIĆ Marija KAUZLARIĆ Ivan, 20 may 1850 / 19 jun 1878/GOLIK Franka KAUZLARIĆ Ivan, 23 jun 1856/24 jun 83/ STARČEVIĆ Marija KAUZLARIĆ Ivan, 24 jun 1799/7 feb 1821/KAUZLARIĆ Jela KAUZLARIĆ Jakob Jače, 19 jul 1837/22 oct 66/ KRAJAČIĆ Katar. KAUZLARIĆ Jakob, 29 apr 1760/11 jan 1782/ GRENKO Katarina KAUZLARIĆ Josip, 17 mar 1819/18 sep 1854/BUTKOVIĆ Jela KAUZLARIĆ Juraj, 13 apr 1856/9 oct 1882/GOLIK Barbara KAUZLARIĆ Luka, 17 oct 1827/25 nov 1852/ NOVINC Katarina KAUZLARIĆ Miha 16 sep 1801/24 nov 1825/ŠTIMAC Marija
$\mathrm{K} / \mathrm{K}$
$\mathrm{K} / \check{\mathrm{C}}$
$\mathrm{K} / \mathrm{K}$
$\mathrm{K} / \mathrm{K}$
$\mathrm{K} / \check{\mathrm{C}}$
$\mathrm{K} / \mathrm{C}$
$\mathrm{K} / \mathrm{K}$
$\mathrm{K} / \mathrm{K}$
$\mathrm{K} / \mathrm{K}$
K/Čk
$\mathrm{K} / \mathrm{K}$
$\mathrm{K} / \check{S}$
$\mathrm{K} / \mathrm{K}$
$\mathrm{K} / \mathrm{K}$
$\mathrm{K} / \mathrm{K}$
$\mathrm{K} / \mathrm{K}$
$\mathrm{K} / \check{C}$
$\mathrm{K} / \check{C}$
$\mathrm{K} / \mathrm{K}$
$\mathrm{K} / \check{C}$
$\mathrm{K} / \mathrm{K}$
$\mathrm{K} / \mathrm{K}$
$\mathrm{K} / \mathrm{K}$
$\mathrm{K} / \mathrm{K}$
$\mathrm{K} / \check{C}$
$\mathrm{K} / \mathrm{K}$
$\mathrm{K} / \mathrm{K}$
$\mathrm{K} / \mathrm{K}$
$\mathrm{K} / \check{C}$
$\mathrm{K} / \mathrm{K}$
$\mathrm{K} / \check{C}$
$\mathrm{K} / \check{C}$
$\mathrm{K} / \check{C}$
$\mathrm{K} / \mathrm{K}$
$\mathrm{K} / \check{S}$
$\mathrm{K} / \mathrm{K}$
$\mathrm{K} / \mathrm{K}$
$\mathrm{K} / \mathrm{K}$
$\mathrm{K} / \mathrm{S}$
$\mathrm{K} / \mathrm{K}$
$\mathrm{K} / \check{C}$
$\mathrm{K} / \mathrm{K}$
$\mathrm{K} / \check{C}$
$\mathrm{K} / \mathrm{K}$
$\mathrm{K} / \mathrm{K}$
$\mathrm{K} / \mathrm{K}$ 
KAUZLARIĆ Nikola, 2 dec 1757/18 feb 1781/ ŠTIGLIĆ Katarina

$\mathrm{K} / \mathrm{K}$

KAUZLARIĆ Pavle, 8 jan 1836/7 oct 1866/MODIĆ Marija

$\mathrm{K} / \mathrm{K}$

KAUZLARIĆ Petar, 6 jul 1837 / 1 aug 1869/ LISAC Marija

$\mathrm{K} / \mathrm{K}$

KAUZLARIĆ Petar, 6 jul 1837/ 1 aug 1869/ LISAC Marija

$\mathrm{K} / \mathrm{K}$

KAUZLARIĆ Toma, 7 mar 1840/4 oct 1868/ KRAJAČIĆ Polona

$\mathrm{K} / \check{\mathrm{C}}$

\section{PAČEVKINI}

KAUZLARIĆ Andre, 28 nov 1779/19 nov 00/BLAŽEVIĆ Marija

KAUZLARIĆ Anton, 11 jan 1748/ 23 feb 1772/ ŠPORER Margareta

KAUZLARIĆ Anton, 12 jan 1863/29 sep 1886/ KAUZL. Elizabeta

KAUZLARIĆ Anton, 26 may 1816/12 nov 1837/ RAČKI Antonija

KAUZLARIĆ Anton, 7 jun 1811/ 23 feb 1832/ BLAŽEVIĆ Antonija

KAUZLARIĆ Blaž, 2 feb 1865/6 jul 1890/BLAŽEVIĆ Josipa

$\mathrm{K} \check{c} / \mathrm{K}$

$\mathrm{K} \check{c} / \mathrm{K}$

$\mathrm{K} / \mathrm{K}$

$\mathrm{K} / \mathrm{K}$

$\mathrm{K} / \mathrm{K}$

$\mathrm{K} / \mathrm{K}$

KAUZLARIĆ Damaz, 12 dec 1875/28 aug 1897/ MAROTI Marija

KAUZLARIĆ Franjo, 4 oct/9 feb 1852/SUČIĆ Marija

$\mathrm{K} / \mathrm{K}$

$\mathrm{K} / \check{C}$

KAUZLARIĆ Gabrijel, 28 mar 1872/22 oct 1899/BLAŽEVIĆ Lucija

$\mathrm{K} / \mathrm{K}$

KAUZLARIĆ Grga, 12 mar 1837/31 aug 1862/ BRNČIĆ Marija

KAUZLARIĆ Grga, 13 mar 1837/18 may 1862/RAČKI Franciska

KAUZLARIĆ Ignac, 31 jan 1865/26 may 1889 KAUZLARIĆ Dorka

KAUZLARIĆ Ivan, 18 may 1849 /5 jun 1872/ VENE Ursula

KAUZLARIĆ Ivan, 4 mar 1844/<1881>/ 2.ž CRNKOVIĆ Franka

KAUZLARIĆ Ivan, 7 jun 1755 /25 jan 1779/ AKAČIĆ Ursula

KAUZLARIĆ Jakob, 14 jul 1757 /25 nov 1781/ ANTIĆ Matejka

KAUZLARIĆ Jakob, 24 jul 1820/4 nov 46/MARUŠIĆ Antonija

KAUZLARIĆ Jakob, 24 jul 1820//KRUŽIĆ Paulina

KAUZLARIĆ Josip, 7 feb 1800/10 nov 1825/CAR Lucija/

KAUZLARIĆ Josip, 7 feb 1800//BUBANJ Jela

KAUZLARIĆ Josip, 8 may 1822/20 jul 1845/ TROHAR Ivana

KAUZLARIĆ Juraj, 8 apr 1875/22 jun 1900/PAVLIĆ Antonija

KAUZLARIĆ Jure Mede, 13 apr 1787/23 feb 1819/KANJER Antonija

KAUZLARIĆ Jure, 21 mar 1717 /<1747>/PROŠEN Margareta

KAUZLARIĆ Ladislav, 27 jun 1859/18 aug 1886/ BLAŽEVIĆ Polona

KAUZLARIĆ Luka, 10 oct 1824 / 1752/ MESIĆ Katarina iz Oštarija

KAUZLARIĆ Luka, 4 oct 1829 /22 nov 1857/ MIHALJEVIĆ Ivana

KAUZLARIĆ Marko, $<1725>/<1745>$ / BATISTIĆ Margareta

KAUZLARIĆ Marko, 22 apr 1682/<1716/Marina, Mar Marg.

KAUZLARIĆ Mate Marinkin, 21 feb 1783/<02/OŽURAMarija

KAUZLARIĆ Mate Marinkin, 21 feb 1783//HORAČEK Ana

KAUZLARIĆ Miha Mežnjar, 2 sep 1785/<1815>/ GRENKO Lucija

KAUZLARIĆ Miha Mišo, 20 nov 1718/ <1748>/ . . Marija, Mara

KAUZLARIĆ Pavle, 24 jan 1804 /7 feb 1828/ ŠVOB Jela

$\mathrm{K} / \check{C}$

$\mathrm{K} / \mathrm{K}$

$\mathrm{K} / \mathrm{K}$

$\mathrm{K} / \mathrm{K}$

$\mathrm{K} / \mathrm{S}$

$\mathrm{Kč} / \check{C}$

$\mathrm{Kč} / \check{C}$

K/Č

K/Č

$\mathrm{Kč} / \check{C}$

Kč/Č

$\mathrm{K} / \mathrm{K}$

$\mathrm{K} / \check{S}$

Kč/Š

K/Č

$\mathrm{K} / \mathrm{K}$

$\mathrm{K} / \check{S}$

$\mathrm{K} / \mathrm{K}$

K/Č

$\mathrm{K} / \mathrm{K}$

$\mathrm{Kč} / \mathrm{K}$

$\mathrm{Kč} / \mathrm{K}$

$\mathrm{Kč} / \mathrm{K}$

$\mathrm{K} / \mathrm{K}$

$\mathrm{K} / \mathrm{K}$

KAUZLARIĆ Stjepan, 18 aug 1831/1 sep 1861/ KAUZLARIĆ Marija

$\mathrm{K} / \mathrm{K}$

KAUZLARIĆ Stjepan, 20 aug 1755/31 jan 1779/ KLOBUČAR Antonija

$\mathrm{K} / \mathrm{K}$

KAUZLARIĆ Stjepan, 25 dec 1835/26 may 1867/ KAUZL. Marija

KAUZLARIĆ Toma, 1772, //TURK Margareta?

$\mathrm{K} \check{c} / \mathrm{K}$

KAUZLARIĆ Vinko, 22 jan 1839/18 may 1865/KARLOVIĆ Josipa

LUKINIĆI

$\mathrm{K} / \mathrm{K}$

$\mathrm{K} / \mathrm{K}$

KAUZLARIĆ Andrija, 16 nov 1793 // OŽBOLT Katarina

$\mathrm{K} / \mathrm{K}$

KAUZLARIĆ Anton,12 jun 1836//KAUZLARIĆ Marija

$\mathrm{K} / \mathrm{K}$ 
KAUZLARIĆ Anton, 12 jun 1836/3 may 1880/SKOČILIĆ Lucija KAUZLARIĆ Anton, 29 dec 181o/4 feb 1832/ŠPORER Polona KAUZLARIĆ Anton, 6 jan 1860/18 may 1884/GRENKO Antonija KAUZLARIĆ Anton, 8 jan 1782 // SUPERIĆ Matejka KAUZLARIĆ Bernardo, 1 sep 1861 /2 aug 1891/POŽARIĆ Franka KAUZLARIĆ Blaž,15 jan 1870/4 oct 1896/RAČKI Antonija KAUZLARIĆ Blaž, 15 jan 1870//Buneta Marija KAUZLARIĆ Blaž, 2 feb 1793/<1813>/ MIHALJEVIĆ Jela KAUZLARIĆ Florijan Ljudevit,5 may 1861/29 jul 83/BUBANJ Marij KAUZLARIĆ Franjo, 28 mar 1852/22 aug 1879/ŠTANFEL Marija KAUZLARIĆ IvanStovrak, 10 may 1829/29 jan 56/JOVAN.Vicenca KAUZLARIĆ Ivan Stovrak, 10may 1829/11 may 74/ TADEJ Mar. KAUZLARIĆ Ivan, 22 jun 1854/18 jul 1880/ GRENKO Marija KAUZLARIĆ Jakob, 5 jul 1799 /1 mar 1824/ LISAC Marija KAUZLARIĆ Juraj, 22 apr 1865/ 11 jul 1889/ BURIĆ Alojzija KAUZLARIĆ Jure 1732/26 sep 1756/LUKINI Marija Margareta KAUZLARIĆ Jure Paškval, 22 apr 1822/21 jun 46/LONČARIĆ Marija KAUZLARIĆ Lovro $<1723>/<1759>$ / ABRAMOVIĆ Agneza KAUZLARIĆ Luka, 18 oct 1834 /22 sep 1863/ ČEBUHAR Marija KAUZLARIĆ LUKINIĆ Toma, 19 feb 1756/2 feb 1779/ŽAGAR Ursula KAUZLARIĆ Ljudevit, 12 aug 1830/7 aug 1855/SMOKVINA Ursula KAUZLARIĆ Martin, 3 nov 1825 /<1861>/ GOLIK Katarina KAUZLARIĆ Matija, /<1834>/ BARETIĆ Margareta KAUZLARIĆ Miha, 27 sep 1726/17 feb 1754/ GAŠPARAC Marina KAUZLARIĆ Pavle, 10 jan 1768/2 may 1788/ SITAR Kata KAUZLARIĆ Pavle, 10 jan 1768/14 nov 1892/ GRENKO Mar Marg KAUZLARIĆ Pavle,13 jan 1851/13 aug 76/ČEBUHAR Ludovika Vic. KAUZLARIĆ Šimun,28 oct 1820//IVANČIĆ Marija KAUZLARIĆ Šimun, 28 oct 1820/3 oct 1857/POLIĆ Marija KAUZLARIĆ Valentin, 12 feb 1860/19 jul 1885/ŠVOB Marija KAUZLARIĆ Vinko, 15 mar 1883/26 jun 1900/KAUZLARIĆ Antja SUČEVI

KAUZLARIĆ Blaž Matija 28 jan 1770/26 nov 1789/ ABR. Mar KAUZLARIĆ Blaž Matija,28 jan 1770//ABRAMOVIĆ Jela KAUZLARIĆ Andre 30 nov 1843/4 mar 1886 / GRENKO Katarina KAUZLARIĆ Andre Nikola, 30 nov 1808/1mar32/GOLIK Jela KAUZLAARIĆ Andre Nikola, 30 nov 1808 //MIHALJEVIĆ Marija KAUZLARIĆ Andre, 11 feb 1839/22 may 1862 /KOVAČEVud Ivana KAUZLARIĆ Andre, 11 feb 1839//STARČEVIĆ Jelena KAUZLARIĆ Anton, 17 jan 1840/19 jun 1872/ŠVOB Katarina KAUZLARIĆ Anton, 19 may 1875/ 20 feb 1898/ KOVAČEVIĆ Mar KAUZLARIĆ Anton, SUDAC,24 may $1733<1754>/ S ̌ V R L J U G A ~ A n a$ KAUZLARIĆ Anton, SUDAC, 24 may 1733//PAŠKVAN Ana KAUZLARIĆ Anton,9 jun 1822/4 nov 1860/ MELFER Mihaela KAUZLARIĆ Bartol, 26 jul 1828/23 sep 1854/ KAUZLARIĆ Antja KAUZLARIĆ Bartol, 5 aug $1762 /<1798>/$ MIHALJEVIĆ Jela KAUZLARIĆ Grga, 10 mar 1870/10 jul 1895/CRNIĆ Marija KAUZLARIĆ Ivan, 13 apr 1835 /18 oct 1857/ ČEPUTAR Barbara
$\mathrm{K} / \mathrm{K}$
$\mathrm{K} / \mathrm{K}$
$\mathrm{K} / \mathrm{K}$
$\mathrm{K} / \check{C}$
$\mathrm{~K} / \mathrm{C}$
$\mathrm{K} / \mathrm{K}$
$\mathrm{K} / \mathrm{K}$
$\mathrm{K} / \mathrm{K}$
$\mathrm{K} / \check{C}$
$\mathrm{~K} / \mathrm{K}$
$\mathrm{K} / \mathrm{K}$
$\mathrm{K} / \check{C}$
$\mathrm{~K} / \mathrm{K}$
$\mathrm{K} / \mathrm{K}$
$\mathrm{K} / \check{C}$
$\mathrm{~K} / \check{C}$
$\mathrm{~K} / \mathrm{K}$
$\mathrm{K} / \mathrm{K}$
$\mathrm{K} / \mathrm{K}$
$\mathrm{K} / \mathrm{K}$
$\mathrm{K} / \check{C}$
$\mathrm{~K} / \mathrm{K}$
$\mathrm{K} / \check{C}$
$\mathrm{~K} / \mathrm{K}$
$\mathrm{K} / \mathrm{K}$
$\mathrm{K} / \mathrm{K}$
$\mathrm{K} / \mathrm{K}$
$\mathrm{K} / \check{C}$
$\mathrm{~K} / \check{C}$
$\mathrm{~K} / \mathrm{K}$
$\mathrm{K} / \mathrm{K}$
$\mathrm{K} / \mathrm{K}$
$\mathrm{K} / \mathrm{K}$
$\mathrm{K} / \mathrm{K}$
$\mathrm{K} / \mathrm{K}$
$\mathrm{K} / \mathrm{K}$
$\mathrm{K} / \mathrm{K}$
$\mathrm{K} / \check{C}$
$\mathrm{~K} / \check{S}$
$\mathrm{~K} / \mathrm{K}$
$\mathrm{K} / \check{C}$
$\mathrm{~K}$
$\mathrm{~K}$ 
KAUZLARIĆ Ivan, 18 may 1849 /5 jun 1872/ VENE Ursula

$\mathrm{K} / \mathrm{K}$

KAUZLARIĆ Jakob, 7 jul 1834/5 jul 1858/ BLAŽEVIĆ Tereza

$\mathrm{K} / \mathrm{K}$

KAUZLARIĆ Jakov, 23 jul 1869 /13 aug 1890/ ŠTANFEL Marija

$\mathrm{K} / \mathrm{K}$

KAUZLARIĆ Josip Blaž, 4 feb 1807/17 feb 30/FORENBAHER Antja

$\mathrm{K} / \check{\mathrm{C}} \mathrm{k}$

KAUZLARIĆ Julijan, 9 feb 1872/17 jun 1897/ BUBANJ Margareta

KAUZLARIĆ Luka, 2 oct 1779/20 nov 1799/POLIĆ Ursula

$\mathrm{K} / \check{C}$

$\mathrm{K} / \check{\mathrm{C}}$

KAUZLARIĆ Martin,3 nov 1799/<1822>/ISKRA Katarina

$\mathrm{K} / \mathrm{S}$

KAUZLARIĆ Miha, 16 sep 1797/21 oct 19/STARČEVIĆ Marija

$\mathrm{K} / \check{S}$

KAUZLARIĆ Miha, 16 sep 1797/26 may 1857/GAŠPARAC Margareta

$\mathrm{K} / \mathrm{K}$

KAUZLARIĆ Miha, 25 sep 1755/28 nov 1773/PAŠKVAN Marija

KAUZLARIĆ Miha, 9 oct 1819/<1856>/ KARLIĆ Margareta

$\mathrm{K} / \check{\mathrm{C}}$

$\mathrm{K} / \check{\mathrm{C}}$

KAUZLARIĆ Stanislav, 8 may 1861/9 jun 1900/GLAD Marija

KAUZLARIĆ Stipan, 25 dec 1865/3 oct 1889/SEKARDI Marija

KAUZLARIĆ Stjepan, 18 aug 1787/<1814>/STARČEVIĆ Marija

KAUZLARIĆ Stjepan,18 aug 1787//ŠTIGLIĆ Antonija

KAUZLARIĆ Stjepan, 3 jan 1806/27 feb 1827/ KAUZLARIĆ Marija

KAUZLARIĆ Stjepan, 11 aug $/<1865>/$ LEVAR Vicka

$\mathrm{K} / \mathrm{K}$

$\mathrm{K} / \check{C}$

$\mathrm{K} / \check{\mathrm{S}}$

$\mathrm{K} / \check{C}$

$\mathrm{K} / \mathrm{K}$

$\mathrm{K} / \check{C}$

KAUZLARIĆ Stjepan, 8 dec 1815/25 nov 1838/RAČKI Ana

$\mathrm{K} / \mathrm{K}$

KAUZLARIĆ Toma, 15 oct 1809/18 nov 35/KAUZLARIĆ ABR. Marija

$\mathrm{K} / \mathrm{K}$

KAUZLARIĆ Toma, 9 mar 1765 /22 nov 1784/ TIJAN Antonija

$\mathrm{K} / \check{\mathrm{C}}$

KAUZLARIĆ Vicko jul 1846 / 28 jan 1875/ČEBUHAR Rozalija

ŽUPANOVI

KAUZLARIĆ Andre, 1 jul 1869/4 oct 1896/ MALINAR Marija

$\mathrm{K} / \mathrm{K}$

KAUZLARIĆ Andre, 10 may 1863/21 jun 1890/BRUKETTA Marija

$\mathrm{K} / \mathrm{K}$

KAUZLARIĆ Andre, 5 jul 1838/ 1 jun 1862/ BLAŽEVIĆ Franciska

KAUZLARIĆ Andre, 5 jul 1838/1 jun 1862/BLAŽEVIĆ Franciska

KAUZLARIĆ Andre, 5 jul 1838/2 aug 1888/ ŠTIMAC Marija

KAUZLARIĆ Anton, 16 jun 1788/<1819>/ GAŠPARAC Antonija

KAUZLARIĆ Franjo 14 oct 1842/31 jun 1867/ GRENKO Paulina

$\mathrm{K} / \check{\mathrm{C}}$

$\mathrm{K} / \mathrm{K}$

$\mathrm{K} / \mathrm{K}$

$\mathrm{K} / \mathrm{K}$

$\mathrm{K} / \mathrm{K}$

$\mathrm{K} / \mathrm{K}$

KAUZLARIĆ Franjo, 14 apr 1844 / 23 oct 1870/ KLARIĆ Margareta

$\mathrm{K} / \mathrm{K}$

KAUZLARIĆ Grga, 7 mar 1783/22 feb 03/ FORENBAHER Antonija

$\mathrm{K} / \mathrm{Kč}$

KAUZLARIĆ Ivan 24 jun 1818/ 7 jun 1835/ BENAC Katarina

KAUZLARIĆ Ivan, 27 dec 1781/1 feb 1801/ KLOBUČAR Jelena

$\mathrm{K} / \check{C}$

$\mathrm{K} / \mathrm{K}$

KAUZLARIĆ Ivan, 27 dec 1781//BLAŽEVIĆ Jela

$\mathrm{K} / \mathrm{K}$

KAUZLARIĆ Ivan, 28 oct 1838/1863/ KARLOVIĆ Ana

$\mathrm{K} / \mathrm{K}$ ?

KAUZLARIĆ Ivan, 28 oct 1838/25 feb 1873/KAUZLARIĆ Antonija

$\mathrm{K} / \mathrm{K}$

KAUZLARIĆ Josip, 14 mar 1826/?/ PAŠKVAN Katarina

K/Č

KAUZLARIĆ Josip, 14 mar 1826/1865/ ŽAGAR Marija

$\mathrm{K} / \mathrm{K}$

KAUZLARIĆ Josip, 19 mar 1866/16nov1890/ BUDISELIĆ Marija

KAUZLARIĆ Juraj, 1 apr 1874/20 aug 1899 /ŠPORER Marija

$\mathrm{K} / \mathrm{K}$

$\mathrm{K} / \mathrm{K}$

KAUZLARIĆ Jure, 1683 /<1720>/Marija Margareta iz Delnica

$\mathrm{K} / \mathrm{K}$

KAUZLARIĆ Jure, 30 mar 1814/13 nov 1834/ GOLIK Marija Marg.

$\mathrm{K} / \mathrm{K}$

KAUZLARIĆ Kuzma Damj 15 sep 1828/18 feb 1849/ LISAC Matejka

$\mathrm{K} / \mathrm{K}$

KAUZLARIĆ Ludvik 16 aug 1830/10 feb 1861/KLARIĆ Lucija

$\mathrm{K} / \mathrm{K}$

KAUZLARIĆ Luka, 15 oct 1840/15 sep 1867/BUBANJ Rosa

K/Č 
KAUZLARIĆ Martin, 4 nov 1804/25 nov 1822/OŽBOLT Antonija

KAUZLARIĆ Pavle, ŽUPAN, 1721//Katarina Bakarka

KAUZLARIĆ Pavle, ŽUPAN, 1721//Margareta Bakarka

KAUZLARIĆ Pavle, ŽUPAN, 1721//MIKOČ ud. Jela

KAUZLARIĆ Stjepan, 15 dec 1793 /1 feb 1819/ BUDISEL Marija

KAUZLARIĆ Stjepan, 15 dec 1793/29 jan 1835/ KAUZLARIĆ Marija

KAUZLARIĆ Šimun, 1760/<1779>/ŠTANFEL Marina Margareta

KAUZLARIĆ Šimun, 18 feb 1872/18 oct 1896/ BLAŽINA Antonija

KAUZLARIĆ Toma, 25 dec 1780/20 feb 1797/ ŠVOB Marija Marg.

KAUZLARIĆ Toma, 19 feb 1752/24 feb 1767/CENČIĆ DVORAN Kata

KAUZLARIĆ Toma, 19 feb 1752//BLAŽEVIĆ Marija

KAUZLARIĆ Toma, 25 dec 1780/20 feb 1797/ŠVOB Marija Marg.

\section{NEIDENTIFICIRANI}

KAUZLARIĆ Anton,//1823</ GAŠPARAC Antonija

KAUZLARIĆ Anton //KRUŽIĆ Jela

KAUZLARIĆ Anton, // STARČEVIĆ Marija

KAUZLARIĆ Anton, //KAUZLARIĆ Antonija

KAUZLARIĆ Anton, <1790>/<1818>/ GRGURIĆ Marija

KAUZLARIĆ Franjo, 3 dec 1823/<1851>/ KRUŽIĆ Polona

KAUZLARIĆ Franjo, 3 oct 1884/26 may 1867/RAČKI Polona

KAUZLARIĆ Grga, $<1885>/<1815>$ / RANDELJ Katarina

KAUZLARIĆ Ivan $<1835>/ 1887>/$ MIHALJEVIĆ Marija

KAUZLARIĆ Ivan, /1820/<1843>/ STIPANOVIĆ Marija

KAUZLARIĆ Ivan, $<1800>/<1824>/$ ABRAMOVIĆ Jela

KAUZLARIĆ Ivan, 18 jul 1875/20 aug 1899/KAUZLARIĆ Katarina

KAUZLARIĆ Ivan, 23 jun 1847/ 28 sep 1871/ PETROVIĆ Marija

KAUZLARIĆ Ivan, 6 feb 1873 /27 jul 1897/ MANCE Matejka

KAUZLARIĆ Jure, $<1800>\mid<1823>/$ GRENKO Katarina

KAUZLARIĆ Lovro, $<1810>/<1835>/$ KUČAN Marija

KAUZLARIĆ Luka// GOLIK Ursula

KAUZLARIĆ Martin // KAUZLARIĆ Mateja

KAUZLARIĆ Matija // ISKRA Ana

KAUZLARIĆ Matija, //OŽBOLT Ana

KAUZLARIĆ Miha //<1830>/ LISAC Margareta

KAUZLARIĆ Miha Patakun// <1826>/ ŠTIMAC Jela

KAUZLARIĆ Miha//<1807>/ŠTANFEL Jela

KAUZLARIĆ Miha//<1823>/ KRUŽIĆ Jela

KAUZLARIĆ Miha//<1843>/ KARLIĆ Margareta

KAUZLARIĆ Paval, 28 jun 1866 /19 sep 1903/MIHALJEVIĆ Romana

KAUZLARIĆ Stjepan /<1830>/ SUPERIĆ Marija

KAUZLARIĆ Stjepan, //KOVAČEVIĆ Marija

KAUZLARIĆ Stjepan, /1755/10 feb 1802/ KAUZLARIĆ Ursula

KAUZLARIĆ Toma, 7 mar 1868/9 jun 1895/ GRENKO Ursula
$\mathrm{K} / \mathrm{K}$

$\mathrm{K} / \check{\mathrm{C}}$

$\mathrm{K} / \check{\mathrm{C}}$

$\mathrm{K} / \check{\mathrm{C}}$

$\mathrm{K} / \check{S}$

$\mathrm{K} / \mathrm{K}$

$\mathrm{K} / \mathrm{K}$

$\mathrm{K} / \mathrm{C}$

$\mathrm{K} / \mathrm{K}$

$\mathrm{K} / \mathrm{K}$

$\mathrm{K} / \mathrm{K}$

$\mathrm{K} / \mathrm{K}$

$\mathrm{K} / \mathrm{K}$

K/Č

$\mathrm{K} / \mathrm{S}$

$\mathrm{K} / \mathrm{K}$

$\mathrm{K} / \mathrm{K}$

$\mathrm{K} / \mathrm{C}$

$\mathrm{K} / \mathrm{K}$

$\mathrm{K} / \check{C}$

K/K

$\mathrm{K} / \check{C}$

$\mathrm{K} / \mathrm{K}$

$\mathrm{K} / \mathrm{K}$

$\mathrm{K} / \mathrm{C}$

$\mathrm{K} / \mathrm{K}$

$\mathrm{K} / \mathrm{K}$

$\mathrm{K} / \mathrm{C}$

$\mathrm{K} / \mathrm{K}$

$\mathrm{K} / \mathrm{K}$

$\mathrm{K} / \mathrm{S}$

$\mathrm{K} / \mathrm{K}$

$\mathrm{K} / \mathrm{K}$

$\mathrm{K} / \mathrm{K}$

$\mathrm{K} / \mathrm{K}$

K/Č

$\mathrm{K} / \check{C}$

$\mathrm{K} / \mathrm{K}$

$\mathrm{K} / \check{C}$

$\mathrm{K} / \mathrm{C}$

$\mathrm{K} / \mathrm{K}$

$\mathrm{K} / \mathrm{K}$ 


\section{CONTRIBUTION TO RESEARCH WORK ON THE BASIC KAJKAVIAN VERNACULAR SPOKEN IN FUŽINE, GORSKI KOTAR}

(Research work on the Fužine parish vernacular's basis, in view of the forming and transformations of indigenous families during the $18^{\text {th }}$ and $19^{\text {th }}$ centuries)

By Zlata Bujan-Kovačević, Zagreb/Samobor

\section{Summary}

With her research work on the marriages between Kajkavians to Chakavians and Shtokavians based on anthroponymic literature, the Fužine parish register of birth, marriage and death, as well as other documents, the paper's author proves that the old basis, i.e. vernacular substrate of the three westernmost Kajkavian-speaking settlements (Fužine, Vrata, Belo Selo) is of the Pokupsko area Kajkavian dialect provenance, altering with the inflow of Chakavians during the $18^{\text {th }}$ and $19^{\text {th }}$ centuries, whereas the Shtokavian dialect of the neighbouring Lič settlement made no impact.

If research work is done evenly in both the Kajkavian homes as in those with mixed marriages, starting from the first census in the middle of the $18^{\text {th }}$ century to the beginning of the $20^{\text {th }}$ century when a significant, nearly complete loss of domestic vernacular takes place, this idiom is in fact Kajkavian, and not Chakavian-Kajkavian, as was erroneously presented a hundred years ago and still is presented to date.

Key words: the Fužine vernacular's Kajkavian substrate; marriages to Chakavians; more reliable informers; original prosody; Rački and Strohal as wrong models 